\title{
Pressing Pain
}

National Cancer Institute

\section{Source}

National Cancer Institute. Pressing Pain. NCI Thesaurus. Code C101177.

A sensation of discomfort or distress from excess weight or pressure on a specific anatomical location. 